\title{
Adapted Services by University Libraries from the Lockdown to the Post-Pandemic Period: The Case of USST
}

\author{
Donglin $\mathrm{Ge}^{*}$ \\ University of Shanghai for Science and Technology, Shanghai 200093, China \\ *Corresponding author: Donglin Ge, donglinge2014@qq.com
}

\begin{abstract}
As public assembly occupancies, academic libraries in China have been implementing effective strategies in response to the challenges brought by the COVID-19 pandemic since January 2020, in order to meet the teaching, learning, and researching needs of the faculties and students due to the closure of libraries. The library at the University of Shanghai for Science and Technology (USST) is one of the typical cases with significantly increased user access during the pandemic. In this article, a reflection is made on the emergency measures and endeavours by the library in USST to adapt various services, including digital resources guarantee while working remotely, moving from an offline reference service to online ones, extending circulation from an in-door service to an out-door service, the use of social media, and so on, in order to discuss the emerging problems and to analyze the lessons learned. On this basis, this article proposes suggestions for university libraries to realign their development directions and measures to digital collections and online services as well as to improve the vocational skills of librarians in the post-epidemic period, so as to provide more professional, active, and considerate services in the future.
\end{abstract}

Keywords: Academic library; COVID-19; Library services

Publication date: November 2021; Online publication: November 30, 2021

\section{Introduction}

A novel coronavirus that can cause severe pneumonia with high morbidity was detected in 2019 unexpectedly, and it is now known as COVID-19, which has led to a global pandemic. Since the breakout of COVID-19, the priority of both the common people and the government has been to stop any possible spread of the virus. Consequently, on January 26, 2020, during the winter break, the main library and other library branches of USST closed temporarily along with the lockdown of all campuses' offices in response to the declaration of a public health emergency in Shanghai. The same event occurred in almost every university in the country. Thereafter, on January 27, 2020, the Ministry of Education issued an important notice through its official website, proposing that universities should postpone the commencement of the spring semester and students should not be allowed to return to their campuses until the local governments have confirmed a time. After that, the Ministry of Education repeatedly issued notifications on the postponement of the school term every week and advised for class suspension but for learning to be continued. On February 5, the Ministry of Education issued the Organization and Management of Online Teaching in Colleges and Universities During the Epidemic Prevention and Control Period ${ }^{[1]}$.

The time called for online education. Although with the closure of campuses and libraries countrywide, the learning and researching needs of academic library users and even some new information explosively increased, thus bringing new challenges. 
The new challenges and the rapidly changing conditions demand innovation to the services provided by academic libraries. As a result, many academic libraries responded in various ways within three months, and down the road, they even changed their developing directions. These responses do not only have unique features to different sizes and budgets, but also have common features and new problems that need to be solved. The study of these commonalities has guiding significance for future work. Therefore, this paper explores the general law of adapted services under the pandemic situation from the perspective of the author's own personal experience working in a library in regard to the operation of emergency response systems, the adaptation of the library in terms of services, the changes in the way of working after reopening, and what have been learned from these experiences. These questions are worthy for research.

\section{USST's library}

University of Shanghai for Science and Technology (USST) is an application-oriented research university that gives priority to engineering. However, it has a balanced development of engineering, science, economics, management, literature, law, art, and other disciplines. As a key university in Shanghai, it has been acknowledged as a pilot unit of "High-Level Local University" in 2018. On the basis of Shanghai's development strategy, optical engineering, system science, power engineering and engineering thermophysics, mechanical engineering, as well as biomedical engineering are main development directions of USST. This implies that within a limited budget, the library collection and digital resource construction of USST focus on these disciplines. The university is willing to spend money on these disciplines' databases to gather relevant research information, while for other disciplines, regular databases and collections are provided and sometimes, interlibrary loans and document transmissions are relied on.

The university is 115 years old and covers an area of nearly 66 hectares, comprising of 17 schools, with 2,900 teaching faculties, and over 27,000 full-time students. Among them, more than 18,000 are undergraduates and over 9,000 are postgraduates. The teaching faculty and the current students are the main patrons. The 48 formal librarians are required to undertake every new responsibility and potential risk for nearly 30,000 users, having the confidence to expand services without sacrificing the quality of those services even during the pandemic.

\subsection{Adapted services}

The library in USST has 8 departments under the lead of the Curator Office at the beginning of 2020. On the second day after the closure of the library, the library's website posted two notifications to inform the librarians to be prepared for any possible challenges brought by the pandemic. The notifications encouraged the employees to keep calm and be rational in distinguishing right from wrong, identify fake news or rumors on the pandemic, and take advantage of their professions to convey official statistic data as well as scientific epidemic protection information to their families and friends. The employees were also required to keep in touch 24 hours a day and monitor their own body temperature along with their family members'. A report should be made within an hour with any location changes across provinces or cities. Besides the requirements of health protection, the notifications stated that keeping a sense of responsibility and dedication is necessary to ensure a well-operated online service and technical maintenance.

\subsubsection{Resources guarantee}

Based on the requirements of users and principles mentioned in these notifications from the Ministry of Education, Shanghai Municipal Government, and the library's own curator, the emergency work began in an all-round way. Even during the shutdown period, high quality resources were still the first needs of users. Therefore, upon closure, the return of books was suspended and the penalty for first-time delay was 
cancelled. The faculty members and students were encouraged to turn to the online service provided in order to ensure an effective utilization of existing resources. For example, a series of open access (OA) resources were provided for research, and thanks to database providers, part of the online databases that needed to be accessed through VPN systems before the shutdown period could be accessed directly outside the campus IP address range for free in 2020. Right after, a list of complementary tools, such as CiteSpace, NoteFirst, Library Genesis, and Setuna, was recommended for better research experience along with stepby-step guidance ${ }^{[2]}$.

Except existing resources, new resources were constantly being brought into sight. The Acquisition and Processing Department worked extra hours to purchase e-books related to the curriculum for various schools in preparation for the coming semesters since there was a high probability that the at-campus courses would be forced to turn to the online method and in consideration that the students do not have any textbooks at home. The task was urgent and pressing because the regular purchasing of pressbooks and databases continued remotely at a regular pace. Finally, a list of 327 e-books was fashioned by collaboration. Not surprisingly, the campus was closed till the end of April, and online tutoring was adopted for all undergraduate courses during the spring semester. In addition, the lectures and labs in Literature Retrieval courses had been moved to the MOOC platform. That was not the end; the library, in collaboration with the Information Office, grasped the chance to apply to join CARSI (China Education and Research Network Authentication and Resource Sharing Infrastructure) and to synchronize with Shanghai Education authentication alliance. Through CARSI, direct off-campus access without VPN was realized for both the teachers and students to access databases, such as ScienceDirect, Web of Science, CNKI, SpringerLink, IEEE, EBSCO, Emerald, Nature, and other core databases with high speed and unlimited download. For graduating students, whose internship had been seriously affected by the pandemic, the library had also offered help with the writing of their graduation thesis and the completion of their graduation designs through the recommendation of different databases, such as bigan.net.

These increasing resources and visits challenged the capacity of the VPN systems and the server's stability. The Curator Office established a new mechanism that is known as "multi-department reacting in chain." The homepage, databases, and VPN access were tested on a daily basis, and in case of any abnormalities, the Information Office as well as the Acquisition and Processing Department were contacted. In this way, immediate feedbacks could be directed to the corresponding database providers to solve the problems pertaining to accessing the databases. Without this mechanism, it is impossible to ensure an efficient resource access by the users.

The library also extended its service in terms of subject service based on instant messengers, such as QQ and WeChat, to reach end users and ensure the effective utilization of resources. The two groups provided free document delivery of all kinds of literature, free subject selection, free guidance on periodical selection and submission, as well as any work that helped users make good use of the library's online resources and identify key literatures that are worthy of intensive reading. From the beginning of the pandemic to the end of the winter vacation on March 2, the subject services of QQ group and WeChat group responded to 427 documents, about 19,183 pages long. Among them, there were about 224 articles, which came from 97 journals, 44 books and dissertations, and 62 other documents. During this period, 128 new users were added to the WeChat group and 207 new users to the QQ group.

\subsubsection{Reading promotion events}

With online publicity work, the library's special "themed" series, coupled with resource access and epidemic knowledge, gained continuous influence, reminding the employees that holding special online events around World Book Day would add weight to this traditional reading promotion service. Therefore, several activities have been launched through WeChat and the library's website, which include trivia games 
on coronavirus in cooperation with Chaoxing Learning application, online reciting activities to support one another in love during the pandemic, live lectures from famous scholars, and so on, thus enriching the users' home-quarantined life. The new reading promotion platform, which breaks the constraints of time and space, allowed us to reach out to patrons through their mobile devices, obtain immediate feedback, and grow closer to users. Comparing with previous face-to-face activities, participating in online events allows users to use their fragmented time more flexibly and efficiently.

\subsubsection{Reading therapy and mental health care}

Besides playing an indispensable role in improving students' and faculty members' understanding on coronavirus, the library had an opportunity to promote reading therapy. Since public opinion is deeply influenced by mass media and social media, information circulates much faster in the internet age. A long and large exposure to pandemic news results in fear, anxiety, and depression caused by the uncertainty of the disease in addition to the painful and suffering experience shared by patients. In order to avoid users developing vicarious trauma, believing rumors, and being in isolation, reading therapy was offered with a recommended list of e-books on history, literature, science, and culture. In addition, links to databases pertaining to epidemic science knowledge, psychology courses, and lectures were provided as well.

\subsection{Post-pandemic changes in the working manner}

Since March, only a number of staffs were allowed to visit the campus to assist research work and for online tutoring. The university and the library provided masks and disinfectants for those staffs. The librarians took turns to be on duty on a weekly basis. The first thing that was done was to keep the building safe. An infrared thermometer was set up in front of the university for temperature detection. Hand disinfection was mandatory at the main entrance of every building, from the library to the cafeteria. In order to preserve a serious attitude toward the pandemic, registration by name, phone number, and temperature had to be manually written, and the WeLink application was used to record everything. Then, the sterilization of air conditioning systems, seats, computers, elevators, restrooms, etc. was done. The library and campus reopened at the end of April, but only graduating students and graduate students were allowed to return. All undergraduates were allowed return till August. Before August, the maximum number of attendances allowed was up to 1,000 for the Zhanen Memorial Library; retired faculty members are still being restricted till now. The rules were very strict: the distance between people should be more than one meter, masks were required, and they were not allowed to sit face-to-face at opposite sides of the table. The number of attendances were monitored by swiping their ID cards. The real-time and dynamic indoor number of people were monitored through scanning the QR code provided, visiting the website, and through the WeLink application. When it reaches the upper limit, no patrons were allowed to enter the library.

In addition to these actions for prevention purposes, the library also centralized the management of books prior to placing them on the shelves. The books returned by patrons or new books must be placed separately for disinfection to avoid the spread of the virus through books. Moreover, the Curator Office had bought new intelligent bookcases for auto-borrowing and returning as well as those with auto-disinfection technology. These bookcases have been placed at libraries, academic buildings, cafeteria, and students' dormitory, providing convenience and a sense of safety to the students. Users would also receive arrival notices through their WeChat or e-mail, and then the books requested can be picked up at a designated place through contactless service. The upgrade in terms of equipment has provided non-contact services and reduced the probability of spread among users and staffs. 


\section{Thoughts and prospects: lessons learned from these experiences}

"User First, for Service \& Education" is not a mouthing empty slogan, but what is done on a daily basis in the library. During the pandemic period, health was placed first. For example, although some students came to the campus in May, the library kept its pace on pushing notification and reference information online instead of putting up posters in the library. Moreover, the library expanded the content and form of its service to guarantee the resources that users' need.

In general, the core value of the library has been realized, with flexible and imaginative measures, which brought good experiences to users. At least, the library is not left behind by the needs of readers in the information age. Thanks to the hard work and good fortune, the campus has been safe, and users have been satisfied with the adapted services. However, there are some problems. The first is the inadequacy of the library in response to the public health. Before the pandemic, it was believed that systematically cleaning and airing the reading rooms were sufficient; the necessity of regularly disinfecting door handles and keyboards was disregarded. The second is the imbalance of the operation of each department during the pandemic. In addition, the library operations rely excessively on the librarian's personal ability and the ability of each librarian is different, resulting in some librarians being set aside while others dealing with heavy workload. Librarians should be given more motivation and opportunities to improve themselves, in order for libraries to adapt to the changing environment. Finally, in the occurrence of a big crisis, there were many things that could not be done solely, but with collaborations, they were possible. Researchers have appealed that establishing a national teaching reference e-book system and a mobile learning platform for university libraries are necessary and collaborations between universities in the same region and database providers could avoid wasteful duplication works ${ }^{[4,5]}$.

\section{Disclosure statement}

The author declares that there is no conflict of interest.

\section{References}

[1] Ministry of Education, 2020, Organization and Management of Online Teaching in Colleges and Universities During the Epidemic Prevention and Control Period. Ministry of Education of the People's Republic of China. http://www.moe.gov.cn/jyb_xwfb/gzdt_gzdt/s5987/202002/t20200205_41813 1.html

[2] Information Board of University of Shanghai for Science and Technology Library. University of Shanghai for Science and Technology Library. https://ibrary.usst.edu.cn/1471/list.htm

[3] Ma J, Jia Z, Wu Y, 2020, Investigation and Analysis of Reading Promotion Activities in University Libraries During Public Health Emergency. Shanxi Library Journal, (4): 19-24.

[4] Wang B, Zhou C, Chen L, et al., 2020, Actively Integrate into the Overall Situation of Covid-19 Epidemic's Prevention and Control and Practically Innovate the Service Strategy During Extraordinary Period: A Survey on Service Innovation During Epidemic's Prevention and Control of University Libraries in China. Journal of Academic Library, (2): 5-17.

[5] Zhang Q, Li J, 2021, Construction of the Collaborative and Synergetic System in University Library: Taking Tsinghua University as an Example. Journal of Academic Library, (1): 50-55. 